\title{
Dealing with Difference: Building Culturally Responsive Classrooms
}

\author{
Nina Burridge, John Buchanan and Andrew Chodkiewicz
}

\begin{abstract}
Australia continues to develop as a multicultural society with levels of immigration increasing significantly in recent years. The current financial turmoil, continuing threats from terrorism and environmental concerns, have all intensified the challenges of dealing with difference in our society. In response, schools continue to face the challenges of the impact of a range of different cultures, languages and religions among their student and school communities. How effectively schools deal with difference and how well they are supported in their endeavours to build culturally responsive classrooms is a perennial issue for policy makers, teachers and teacher educators. A major challenge for teachers in particular, is to at a minimum, understand cultural differences as they manifest in their particular school settings. Also to draw on approaches that support student learning in culturally appropriate ways so to assist them to better realise their full potential. In this paper we will consider cultural diversity in the context of current school policies, and highlight a number of frameworks for addressing cultural diversity in the classroom. We draw on the findings from a recent qualitative study of representations of cultural diversity in a number of Sydney schools to discuss the need for greater resource and policy support for progressive and innovative teaching approaches that will support the development of inclusive communities.
\end{abstract}

\section{Introduction}

Australia continues to develop as a multicultural society, and schools continue to experience to varying degrees, the opportunities and challenges of accommodating a range of different cultures, languages and religions among their student and school communities. This again raises the need to support schools and teachers in their endeavours to acknowledge and address cultural difference in positive ways and to build more culturally responsive classrooms.

Levels of immigration have increased significantly over recent years as a result of government policies, with 2006-07 the highest year on record. Migration has continued to be the main contributor to the growth of Australia's population (ABS 2008, p.9). At the same time, Australia has emerged from a period of marginalisation of the policies of multiculturalism (Jakubowicz 2006), during which time there was a major focus on notions of social cohesion through an emphasis on 'Australian values'. As Australia, and indeed the world, has moved into a period of financial turmoil, with continuing threats from terrorism and climate change, the challenges of dealing with difference in schools and classrooms remain key issues for both teachers and educators. 
A major challenge continues to be for schools and teachers to, at a minimum, recognise the cultural diversity of our society and in their particular school settings to draw on approaches that support student learning in culturally appropriate ways to assist them to better realise their full potential. It is important to once again focus the efforts of educators to build more culturally responsive classrooms across the many different school and community settings. In part this means continuing to build on the work of teacher educators in Australia (Kalantzis \& Cope 1999; Noble \& Poynting 2000) and overseas (Banks \& McGee 1993; Banks 2003; Gorski 2006) who since the 1970s have been seeking to implement more progressive and creative strategies that support the emergence of a more tolerant and inclusive multicultural society.

In this paper we will consider cultural diversity in the context of recent school policies, using as a reference point a number of frameworks for addressing cultural diversity in the classroom (Kalantzis \& Cope 1999; Hickling-Hudson 2003), and draw on a qualitative study of cultural representations in a number of Sydney metropolitan schools (Burridge \& Chodkiewicz 2008).

\section{Cultural diversity and countering racism}

What do we mean by cultural diversity in educational settings? Definitions and approaches are often influenced by context, including history, location, and the nature of the school, its population and teacher commitment to various policies.

In terms of policy formulation, identity markers for diversity include factors related to culture, language, religion and access to citizenship. One example of how education policy makers define diversity is the NSW Government's Community Diversity and Community Relations policy. It refers to the need for schools to respond to and reflect 'cultural, linguistic and religious diversity' (NSW DET 2005a). At the same time the policy sees difference in terms of enabling students from a variety of backgrounds to access learning and to become active citizens. This means giving students 'the opportunity to fully participate, achieve equitable outcomes, and develop skills and knowledge to be active citizens' (NSW DET 2005a). 
In setting out the principal objectives for schools, the NSW Department of Education and Training (NSW DET) policy focused on a number of overall goals, such as promoting community harmony, countering racism and intolerance, and enabling students from all cultures to identify as Australians. For teachers it meant ensuring that their teaching practices were more inclusive and that students whose first language wasn’t English were being supported to learn English.

At the same time there was also an ongoing focus on countering racism included in the department's policy framework. This was at a time, as shown by a number of recent Australian studies (Dunn et al. 2004; Dreher 2006; Browning \& Jakubowicz 2004), when the community experienced an increase in racist incidents, following the 2001 New York Twin Towers attack. The need to address racism within local communities was affirmed in a recent study by Forrest and Dunn (2007) that demonstrated the way that racist attitudes were concentrated in particular areas, including in some parts of Sydney. The distinctive geography of racial intolerance across Sydney identified by Forrest and Dunn suggested that efforts by schools to deal with diversity and counter racism needed to be designed so that they addressed the specific community contexts of intolerance.

\section{Diversity in New South Wales}

The nature of the diversity of communities in NSW can be seen from 2006 Census Data (ABS, 2007), which presents diversity in terms of country of origin, languages spoken other than English and religion. Notably 21\% of NSW residents were born overseas, $20 \%$ spoke a language other than English at home, and among the fastest growing religions were Hinduism, Islam, and Buddhism. It is also important to note that the cultural, linguistic and religious mix across NSW, and particularly across Sydney, is ever changing over time, as new communities arrive and settle.

The impact on schools of changing community diversity is also evident. Data on the language background of government school students shows that more than one in four, or 26\%, of students in government schools in NSW were students from Language Background Other Than English (LBOTE). Most of these students were located in only three Sydney school regions - South Western, Sydney and Western Sydney (NSW DET 2005, p.5). Among the main languages other than English spoken at home by NSW government school students in 2004 were 36,168 (18\%) students with Chinese; 25, 092 (12.5\%) Arabic; 11,819 (5.9\%) 
Vietnamese; 11,082 (5.6\%) Pacific communities (Samoan, Tongan, Fijian); 7,423 (3.7\%) Tagalog and 6,980 (3.5\%) Hindi.

\section{Educating for cultural diversity}

The importance of teachers educating for cultural diversity and including it as a key part of their work in the classroom was emphasised by Noble and Poynting (2000) who argued that part of the rationale for multicultural education was about the removal of disadvantage, the recognition of the value of cultural pluralism, the need for social cohesion and the benefit of drawing on the language and cultural resources of immigrants. Discourses are also important. Allard \& Santoro (2004) identified three cultural diversity discourses impacting on teachers. One was around the failure of students to achieve, another around the pressures of globalisation and a third arose from the growing mismatch between the backgrounds of teachers and the increasingly diverse student populations they taught.

The failure of a significant proportion of students from some cultural backgrounds, together with students from lower socio-economic backgrounds and Indigenous students, remain major challenges for educators. A way of addressing these challenges was for teachers to develop better understandings of the ways students in these groups could be more effectively engaged in learning and make sense of new knowledge, without negating the cultural knowledge that they brought to their classrooms (Allard \& Santoro 2004).

The pressures of globalisation were also highly influential. As Allard and Santoro (2004, p.2) stated 'the need to prepare students to take their place in a world that will be vastly different from that which we know today' demands of teachers the ability to work productively within increasingly diverse contexts and 'to recognise different ways of knowing and being'.

\section{The teaching profession}

The teaching profession in Australia is overwhelmingly representative of the mainstream community. A comprehensive national survey of over 10,000 teachers in government and non-government schools published in 2001 noted that 'four out of five teachers reported Australia as their country of birth, with another 7.6\% United Kingdom or Ireland... almost ninety percent (89.4\%) of the respondents came from English speaking backgrounds' (ACE 2001, p.2). While some changes to the composition of the teaching profession will have 
occurred since the survey, it is unlikely that that these figures will have altered significantly from that time.

If as educators we take these factors and discourses into account it means that teachers should be being better prepared to become professionally skilled in understanding the pedagogy and learning issues related to cultural diversity. A 2005 report by a Victorian Parliamentary Education and Training Committee included the recommendation that all teachers must be equipped to meet the needs of 'a diverse student population, of which migrant and refugee young people are an essential part' (Allard 2007). The Business Council of Australia noted in 2003 that cultural cohesiveness was a necessity for Australia's economic future. To achieve this, sufficient resources, adequate training and professional development were required (Osler \& Vincent 2003, p. 47).

While educational policies have reinforced the need for teachers to understand and respond to the ways in which a range of factors, including culture and ethnicity, shape the learning experience of their students, the support being provided for their implementation is often limited and fragmented. Much of what is being done is short term and reactive to events in the broader community.

\section{Representations of cultural diversity in schools}

Among the challenges facing educators as Allard and Santoro (2004, p.7) suggested, was how to 'rethink our teacher- education curriculum so that we might more actively engage with our students in examining taken-for-granted discourses around difference and identity.' A starting point continues to be educating teachers about ways of positively engaging with difference in the classroom. This remains crucial, because as has been noted earlier, teachers as a group are drawn from what are largely middle class, Anglo-Australian backgrounds (Allard \& Santoro 2004, p.4). This prompts the question: if teachers generally reflect the values and beliefs of the dominant class, how well are we preparing our teachers to meet the challenges of cultural diversity in our classrooms? In order to gain some insight into this question we present a brief outline of findings from a research project conducted by two of the authors in 2007 and 2008. These findings provide the evidence for the recommendations noted in the final sections of the paper Ways forward. 


\section{Findings about representations of cultural diversity}

A study of representations of cultural diversity in schools by Burridge and Chodkiewicz (2008) cited three case studies that reflected a number of different school and community settings. They ranged from a culturally homogenous or largely monocultural community with a small number of new emerging communities, a monocultural community with a range of many smaller established communities, and a third with a very mixed and culturally diverse community.

In researching schools in three different regions in Sydney the study found:

Pockets of the south/eastern suburbs and northern suburbs of Sydney, including the northern beaches, present themselves as 'clusters of whiteness'. There is little focus on multicultural programs both in schools and in the community settings of some of these areas - particularly at the secondary level. Young people commented on the insularity of some of the attitudes of members of those communities (Burridge \& Chodkiewicz, 2008, p. 38).

The findings, together with Haviland (2008), have pointed to a need, especially in largely mono-cultural areas or what have been described as clusters of 'whiteness', for cultural diversity to be treated as an important issue for both teachers and students.

The study also found that while there were a number of excellent programs in place, generally they were limited and often marginal to what was being taught in the classroom. The study identified a number of different approaches to cultural diversity which could broadly be described as, one, 'taking a reactive' approach; two, the 'showing no interest' approach; or three, taking an 'integrative, whole-school' approach.

In one area, where a high school had experienced a critical incident, that event became a major motivator for the school to take action to address cultural diversity. In that case the school reacted after it saw the impact of the Cronulla Beach riots on its school population. It initiated an inter-school program of cultural exchange as a way of starting to address cultural diversity across the school. The program was seen as an effective way of increasing the level of understanding of other cultures among both students and teachers. It was also a way for students to develop relationships with other students from very different backgrounds to their own. 
In another area where the high school saw itself and its community as being monocultural, because there were only a few small emerging non English speaking communities, the school did not see a need to address any cultural diversity issues, apart from considering the English language needs of a small number of students. This meant providing ESL classes to help students to learn or to improve their English. In the same area a primary school has focused on one of the area's emerging refugee communities, because some refugee children were starting to enroll at the school. The school reacted positively to the change in its school community and even decided to take on a support role with a number of refugee families.

In the third area, which had a highly mixed and culturally diverse community with many recent arrivals, one primary school adopted what could be described as a 'integrative wholeschool' approach. The school said that aspects of cultural diversity were being acknowledged across the school, students of all backgrounds were being included and asked to share their culture at school, and the school worked on being welcoming to parents.

The study noted that only a small number of cultural diversity programs and activities were being implemented in the schools and most were celebration days or cultural exchanges. Celebrations of designated days like Harmony Day, which provided an opportunity to recognise a range of different cultures at a school, were carried out to varying degrees. In addition, it was only in schools that had a significant number of different cultural communities, that a number of national days were also celebrated. Even so, schools reported that they were only able to effectively focus on a few of their largest cultural or linguistic communities.

Inter-school cultural exchanges were seen as a positive way for students and teachers in a school to directly gain experience of other cultures. For one high school it was clear that unless the exchanges had been initiated by the school, neither students nor teachers were likely to have made contact with or gained any direct experience of those cultures during their years at school. Community partnerships, where schools reached out to parents and local community organisations to develop an ongoing relationship, were not evident in the study.

There were examples of a number of schools trying to develop better relations with parents in their school community. Primary schools were the most likely to invite parents from various 
cultural backgrounds into school and to try to make them feel more welcome. Efforts were also being made to communicate more effectively with parents from the largest non-English speaking communities. This was generally done by having documents translated and sending out information about school activities in a newsletter or circular in the main community languages.

\section{Young Muslim voices}

The study also highlighted the struggles students faced with their identity. In particular since 2001, students from Muslim backgrounds reported how they felt they were being forced to struggle between two very different worlds. They said that they had to work through their feelings of having multiple belongings and of feeling that they were being excluded from the mainstream. Their comments showed how they were being forced to question their Australian-ness as a result of their many negative experiences. Girls who wore the hijab said they were being stereotyped and made to feel they were no longer accepted as Australians. For others the colour of their skin had become a major issue.

\section{Ways forward}

The findings of the Burridge and Chodkiewicz (2008) study suggested that there were a number of ways to better support efforts by teachers to build more culturally responsive schools and classrooms. These included a re-evaluation by policy makers of the cultural diversity frameworks that currently informed school and community based policies and programs across school education sectors.

\section{Approaches}

In capitalising on what has already been achieved by multicultural education programs to date, while seeking to respond to the existing realities of cultural diversity across school communities, it is useful to consider possible frameworks in planning policies and strategies in educating for cultural diversity.

One approach that could be used to inform policy makers, as outlined by Kalantzis and Cope (1999) argued for the need to move towards a more progressive critical approach to cultural diversity, rather than taking an assimilationist or a pluralist approach. They focused on what they saw as the need to 'transform the mainstream' by implementing 'an explicit pedagogy of inclusion and access' (Kalantzis \& Cope 1999, p. 253). Among the general principles they 
developed were transforming the core culture by developing multilayered allegiances between groups and communities, transforming the mainstream curriculum in response to cultural and linguistic diversity, and the placement of diversity as a core issue within the curriculum (p.273).

Another approach, developed by Anne Hickling-Hudson (2003, set out to address the contesting discourses of cultural diversity and move beyond just the promotion of contact with other cultures, food and festivals. Arguing for the development of an interculturally proactive school, her approach aimed to develop a school where 'most teachers are constantly active in designing and implementing programs and strategies to promote intercultural understanding and inter-relationships' (p.2). Among the main strategies outlined were liaison between teachers and parents drawn from the different communities at the school, critical socio-cultural studies located within the curriculum, and support and promotion for students to study and learn their home language.

With these frameworks in mind, the use of appropriate pedagogical practices in the classroom are needed as a key way to implement change in how schools approach cultural diversity. This implies implementing change at the practical level with in-class strategies, as well as at the theoretical level with professional development activities to ensure that what develops is a deeper understanding of teaching and learning practices in the context of a culturally diverse classroom.

Educational institutions, including schools and universities, need to engage with the debates about representations of ethno-cultural diversity, nationhood and identity. Indeed their contributions can help to shape these discourses. Professional educators in schools need to focus their attention on the roles they play in converting the challenges of cultural diversity into opportunities for all children and young people and to see cultural differences as assets not as a deficit in their students or their community.

As schools address diversity, at the pedagogical curriculum related level, teachers must be supported to better meet the learning needs of students from culturally and linguistically diverse backgrounds. These teachers should be professionally skilled to understand the issues related to links between cultural maintenance and educational outcomes - including first language teaching. 
The charge of supporting teachers in their roles as leaders and shapers of the discourse in their schools and their communities is a challenging task. This is especially the case for beginning teachers, dealing as they are with putting into practice a multiple set of skills, often under difficult circumstances, in a new school environment.

This means there is a need for a renewed program of teacher education about various aspects of cultural diversity. This includes increasing the understanding and awareness of teachers about the new policies and approaches to cultural diversity in schools. Most importantly it means underscoring this with real action in schools, so that the policies are not just seen as window dressing. It is important to offer more support for professional development, both at the pre-service teacher level and in schools, and for it to include all teachers, not just to limit the training to language and ESL teachers.

\section{Tackling the curriculum}

A major challenge is how to achieve meaningful change in the school curriculum. This means addressing what is emphasized and how responsive and reflective of difference the curriculum is. Change is needed in both the curriculum content and how it is taught. In researching the strategies and methods of experienced teachers Allard and Santoro (2004) emphasised the need to find out and communicate what has been found to have worked in classroom settings, and the ways in which teachers could be encouraged and supported to address difference so that they could build more culturally responsive classrooms. While this relates back to the nature of our pre and in-service teacher education, it also points to a lack of conviction by policy makers to move from the rhetoric of policy to actual implementation.

One example of this policy rhetoric relates to the introduction of a new curriculum initiative by the former NSW Premier Morris Iemma in 2006. Citing 'a fundamental lack of respect for authority' as a cause of the Cronulla Beach riots, he introduced a number of initiatives promoting values education under the Respect and Responsibility program. Respect was defined as 'having regards for yourself and others, lawful and just authority and diversity within Australian society and accepting the right of others to hold different or opposing views' (BOS NSW 2007). The main activities schools were asked to focus on were cultural awareness (meaning that diversity within schools and communities was to be celebrated), inter-school programs, cultural exchange, and community partnerships. From the findings 
presented by Burridge and Chodkiewicz (2008) it appears that for many schools the new program has not been translated into a greater concentration of activities on cultural awareness.

Another important area of need is the provision of more curriculum resources to support culturally responsive teaching practices in schools. Although schools have generally been well served with multicultural resources in the past, the findings by Burridge and Chodkiewicz (2008) pointed to the need for better and more updated resources, including ones that addressed religious diversity. In particular there was an urgent need for more resources to help with developing a better understanding of Islam.

\section{School events and cultural exchanges}

Celebrating cultural diversity in schools through the staging of an annual event has been a feature of school responses to multiculturalism over many years. The annual Carnivale day celebration were a major focus and more recently Harmony Day has provided at least one day in the school year to focus on and celebrate cultural difference.

These celebrations are positive expressions of diversity, at least at a symbolic level. In many schools they often affirm a school's approach, where cultural diversity is seen and treated as separate to the school's identity, rather than being something that is an integral part of a school's learning. At the same time celebrations can often provide children and parents from migrant backgrounds their only opportunity over a year to celebrate their heritage, language and culture and get actively involved in their school.

Organising awareness programs or cultural exchanges have been seen as effective ways for schools to provide students with opportunities to meet and interact with fellow students from other cultures. Some schools have been also linking up with other schools internationally by using various web and communication technologies.

It is important to remember that staff face many competing pressures in any school day. Issues of cultural diversity often compete for attention with other social and learning issues. As we suggest school events and cultural exchanges are often viewed as of marginal interest 
to the operation of a school, and there is a need to find ways to link these activities back into particular key curriculum and learning areas.

\section{Counter-racism strategies for teachers}

The importance of effective counter-racism teaching and learning strategies in both preservice and in-service contexts can scarcely be overstated. Given the demographic profile of teachers, teacher education institutions could also be considered as examples of 'clusters of whiteness' as referred to earlier by Burridge and Chodkiewicz (2008, p. 38). This can contribute to what Sunstein (2007, p. 273) identified as 'ideological amplification', where people with similar views tend to associate, mutually echoing and thereby amplifying and normalising, rather than interrogating, their presumptions about social and cultural propriety. The phenomenon operates in both the real and virtual worlds. This circumstance 'only adds to the imperative for programmes that promote sustained and transformative White engagement with anti-racist pedagogies’ (Haviland, 2008: 51, emphasis added).

This situation may be further complicated by the fact that teachers are quite likely to be deployed initially to difficult-to-staff schools (Allard \& Santoro, 2004). These schools are often characterised by student populations that are ethnically and socioeconomically quite different to the background of the teacher. As we mentioned above according to the Australian College of Education survey, 88 \% of teachers identified Australia, the United Kingdom or Ireland as their country of birth, with about nine in every ten being from English speaking backgrounds (ACE 2001, p.2). Given that Catholic and Independent schools are characterised by greater ethnic and linguistic diversity, the numbers of non-English speaking teachers in the State system is likely to be even lower. This stands in stark contrast to the ethnic and linguistic profile of diversity we outlined across NSW schools, and in particular, of the diversity of many of the schools where these teachers will begin their careers.

\section{School - Community links}

Developing links with key local community organisations also continues to be a challenge for many schools. Schools at both primary and secondary levels need to recognise the value of seeing learning in a broader, more culturally inclusive way that includes their wider community. It means devoting more time and staff resources to reach out and involve parents, groups and associations from the wider community. 
This is one area where government support could extend school involvement through the provision of dedicated funding to support the development of partnerships or through targeted community grants programs. Providing grants for schools and communities to organise activities that bring young people together from different cultural backgrounds can further help to bridge the cultural divide. School involvement with the philanthropy sector, by approaches to foundations and other non-profit funds, is another avenue for schools to access community grants to support their work with cultural diversity.

\section{Conclusion}

It is important to acknowledge that there continue to be strongly contested views about how to approach cultural diversity within schools and classrooms. Few studies appear to have been conducted to date on the related strategies adopted by teacher education institutions, and on their outcomes and effectiveness. The environment for the beginning teacher may be quite 'foreign' in a number of respects, for new teachers, it may be the first time that they have had the experience of being, in a local context, part of a cultural minority.

Allard and Santoro (2004, p. 17) pointed to the need for more research into the ways teachers could be supported in developing their own insights into diversity and difference. They emphasised that teachers had to be supported in enabling students to explore and challenge many taken for granted 'truths' about cultural difference. One way of refocusing and building on what has been achieved in multicultural education is to move towards more critical, culturally responsive, progressive approaches to cultural diversity in schools. This implies a redirection of energy and thought towards a genuine commitment by policy makers and teachers to multicultural education. This requires teachers and policy makers to challenge prevailing views that have dominated our public discourse over recent years which see diversity as being a threat to community harmony and national unity.

Supporting a more progressive approach means that policy makers, teacher education institutions, schools and teachers place a greater emphasis on:

- reflecting and representing the existing cultural, linguistic and religious diversity in schools and engaging in community debates about cultural diversity; 
- developing culturally responsive curriculum ideas and strategies that reflect Australia's new migration trends:

- ensuring there is a major focus on linking activities to the curriculum so that programs are embedded into mainstream subjects;

- engaging in the application of innovative web based interactive technologies to curriculum strategies that can be used to link global communities;

- providing more opportunities for students from LBOTE to draw on their cultural backgrounds as part of their school curriculum and school learning activities;

- providing opportunities for students to discuss issues of belonging and identity; and

- building relationships with their local communities including parents, cultural community associations and other key local organisations.

In particular the relationships between schools and their local community should have more depth and involve more than just having guest speakers or celebrations on special days, such as Harmony Day. They should be built on real connections that involve parents, local cultural groups, the local council, as well as the local business community. In this sense the school should become a central point of connection with the community, one that helps to better cement the social fabric of the community.

There are good reasons to be optimistic about these efforts, because as Marginson notes:

Regardless of the homogenising intentions of governments and the techniques of official programs, it is a safe bet that migrants will increasingly pluralise multiculturalism and multicultural education in the future (2004).

Given the increasing diversity in our classrooms, educational authorities and educational policy-makers should endeavour to further develop and build on policies in various school settings that celebrate difference and look to develop a greater sense of unity through diversity. 


\section{References}

Australian Bureau of Statistics 2008, Migration: 2006-07: 3412.0. Australian Bureau of Statistics, Canberra.

Australian Bureau of Statistics 2007, 2006 Census Tables: New South Wales: 20680. Australian Bureau of Statistics, Canberra.

Australian College of Educators 2001, Teachers in Australian Schools: A Report from the 1999 National Survey: Executive Summary [online] Australian College of Educators, Deakin, ACT. http://www.dest.gov.au/sectors/school_education/publications_resources/other_publications/tea chers in australian schools.htm

Allard, A.C. 2007, Testing (my) identities: examining the 'Australian citizen' through the lens of Institutional Ethnography. Paper presented at the International Conference on Institutional Ethnography, Geelong, November, 2007.

Allard, A. and Santoro, N. 2004, Making sense of difference? Teaching identities in postmodern contexts, [online] Paper presented at the Australian Association of Research in Education National Conference, December, Melbourne. http://www.aare.edu.au/04pap/all04561.pdf

Banks, J. A. 2003, Teaching strategies for ethnic studies. Allyn and Bacon, Boston.

Banks, J.A. and McGee Banks, C.A. (eds) 1993, Multicultural Education: Issues and perspectives. $2^{\text {nd }}$ ed., Allyn and Bacon, Boston.

Board of Studies NSW 2007, Respect and Responsibility: Promoting values in education. [online] Board of Studies, NSW, Sydney. http://www.boardofstudies.nsw.edu.au/respect/

Browning, J., and Jakubowicz, A. 2004, Respect and racism in Australia. Discussion Paper No 2, Fair Go Australia and Trans/forming Cultures Research Centre, Sydney: University of Technology, Sydney.

Burridge, N. \& Chodkiewicz, A. 2008, Representations of cultural diversity in school and community settings. Sydney: University of Technology, Sydney.

Department of Education, Employment and Workplace Relations 2008, Values Education 2005 and beyond. Department of Education, Employment and Workplace Relations, Canberra.

Department of Education, Employment and Workplace Relations 2005, Flagpole Funding Initiative (FFI) overview. Department of Education, Employment and Workplace Relations, Canberra.

Department of Education, Employment and Workplace Relations 2001, Teachers in Australian schools: A report from the national survey, Australian College of Education and Department of Education, Employment and Workplace Relations, Canberra.

Dreher, T. 2006, 'Targeted' Experiences of Racism in NSW after September 11, 2001. UTS Shopfront Research Monograph Series No 2, Sydney: University of Technology, Sydney.

Dunn, K. M., Forrest, J., Burnley, I. and McDonald, A. 2004, 'Constructing racism in Australia', Australian Journal of Social Issues, vol. 39, no. 4, pp.409-430.

Eckerman A-K. 1994, One Classroom Many Cultures: Teaching Strategies for Culturally Different Children. Allen and Unwin, Sydney.

Forrest, J. and Dunn, K. M. 2007, 'Constructing racism in Sydney, Australia's largest EthniCity', Urban Studies, vol. 44, no. 4, pp.699-721.

Gorski, P.C. 2006, Complicity with conservatism; the de-politicizing of multicultural and intercultural education. [online] White Paper. EdChange Publications.

Haviland, V. 2008, “"Things get glossed over”: Rearticulating the silencing power of whiteness in education' Journal of Teacher Education, vol. 59, no. 1, pp.40-54.

Hickling-Hudson, A. 2003, 'Towards the Interculturally Proactive School', [online] Curriculum Leadership, January, pp.1-9. 
Jakubowicz, A. 2006, 'Anglo-multiculturalism: contradictions in the politics of cultural diversity as risk’[online] International Journal of Media and Cultural Politics, vol. 2, no. 3.

Kalantzis, M. and Cope, B. 1999, Multicultural education: transforming the mainstream, in S. May (ed) Critical Multiculturalism: Rethinking Multiculturalism and anti-racism education. Falmer Press, London, pp.245-276.

Mansouri, F. and Trembath, A. 2005, 'Multicultural education and racism: The case for ArabAustralian students in contemporary Australia', International Education Journal, vol. 6, no. 4, pp.516-529.

Marginson, S. 2004, 'They Still call Australia Home: Migration Language and Education in Australia', Paper at the Multicultural Futures Conference, 22 -23 September, Monash University, Melbourne.

Martin, J., Tett, L. and Kay, H. 1999, 'Developing collaborative partnerships: limits and possibilities for schools, parents and community education', International Studies in Sociology of Education, vol. 9, no. 1, pp.59-75.

Noble, G. and Poynting, S. 2000, Multicultural education and intercultural understanding: ethnicity, culture and schooling, In S. Dinham and C. Scott (eds) Teaching in context, Australian Council for Educational Research, Camberwell, Vic., pp.56-81.

NSW Department of Education and Training 2005, Statistical Bulletin: Schools and Students in New South Wales, 2004, Planning and Innovation, Department of Education \& Training, Sydney: NSW.

NSW Department of Education and Training 2005a, Cultural Diversity and Community Relations Policy: Multicultural education in schools, [online] NSW Department of Education \& Training, Sydney. https://www.det.nsw.edu.au/policies/student serv/equity/comm rela/PD20050234.shtml

Osler, A. and Vincent, K. 2003, Girls and Exclusion: rethinking the agenda, Routledge Falmer, London.

Sunstein, C. 2007, 'Ideological amplification', Constellations: an international journal of critical and democratic theory, vol. 14, no. 2, pp.273-279. 